|| ISSN(online): 2589-8698 || ISSN(print): 2589-868X || International Journal of Medical and Biomedical Studies

Available Online at www.ijmbs.info

PubMed (National Library of Medicine ID: 101738825)

Index Copernicus Value 2018: 75.71

Original Research Article

Volume 3, Issue 9; September: 2019; Page No. 81-85

\title{
RISK FACTORS FOR DIABETIC FOOT AND LOWER LIMB AMPUTATION
}

\author{
Dr. Uday Prakash ${ }^{1}$, Dr. Kumar Durgeshwar ${ }^{2}$, Dr.R.K.Das ${ }^{3}$, Dr. Lalji Chaudhary ${ }^{4}$ \\ ${ }^{1}$ SR Dept. of Orthopaedics Darbhanga Medical College Laheriasarai Darbhanga. \\ ${ }^{2}$ SR Dept. of General Medicine Darbhanga Medical College Laheriasarai Darbhanga. \\ ${ }^{3}$ Associate Professor Dept. of General Medicine Darbhanga Medical College Laheriasarai Darbhanga. \\ ${ }^{4}$ Prof. and Head Dept. of Orthopaedics Darbhanga Medical College Laheriasarai Darbhanga.
}

Article Info: Received 29 August 2019; Accepted 16 September. 2019

DOI: https://doi.org/10.32553/ijmbs.v3i9.538

Corresponding author: Dr. Kumar Durgeshwar, SR Dept. of General Medicine, Darbhanga Medical College Laheriasarai Darbhanga.

Conflict of interest: No conflict of interest.

\section{Abstract}

Introduction: Diabetic foot syndrome (DFS) is the major cause of hospitalization for diabetes-related complications. Protective sensation loss and impaired vision increase the susceptibility for minor feet trauma, which results in diabetic foot ulceration with or without subsequent infection. Peripheral arterial disease is a major cause of impaired ulcer, wound healing and gangrenous diabetic foot. The most important intervention to prevent diabetic foot ulceration and its consequences is early recognition of high-risk patients and their risk factors and referral to appropriate medical departments. There are various risk factors for major lower extremity amputations related to diabetic foot, which includes microvascular diseases, infections, long duration of diabetes, poor glycemic control, peripheral arterial disease, old age and associated cardiovascular comorbidities.

Material and Methods: This study was done on the review of medical records of consecutive type 2 diabetic patients. Admitted patients were treated and managed according to the standard protocol of the hospital. History, clinical and physical examination were carried out on each patient. Ulcer characteristics like infection and depth of the ulcer, site of ulcer were assessed. Associated diabetic neuropathy and peripheral arterial disease was assessed by a clinical method. Age, sex, body mass index (BMI), smoking, duration of diabetes, diabetic control therapy, associated hypertension, cardiac diseases were recorded. The glycated haemoglobin level (HbA1c) were recorded.

Results: A total of 128 patients with diabetic foot were included in the study of which 76(59.4\%) were male and 52(40.6\%) were female. Of the 76 male 6 (4.7\%) had major amputation and out of 52 female $4(3.1 \%)$ had major amputation, thus total number of major amputations were $10(7.8 \%)$. Statistically significant difference was observed in $\mathrm{HbA} 1 \mathrm{C}$ and duration of diabetes group in amputation. High $\mathrm{HbA} 1 \mathrm{C}$ and more duration of diabetes was associated with the higher number of amputation. The rate of amputation was much higher among patients hypertension, smoking, cardiac diseases and stroke. Conclusion: Poor glycemic controls and duration of diabetes are the important independent risk factors for diabetes-related major lower extremity amputations.

Keywords: DFS, BMI, smkoing, DM

\section{INTRODUCTION}

Diabetic foot syndrome (DFS) is the major cause of hospitalization for diabetes-related complications'. Studies report varying prevalence in type 2 diabetic patients of foot ulceration (2-7\%) and of lower limb amputation $(0.2-4 \%)$ in primary health care ${ }^{\mathrm{ii}}$, iii, iv 3 . Protective sensation loss, and impaired vision increase the susceptibility for minor feet trauma, which results in diabetic foot ulceration with or without subsequent infectionv. Peripheral arterial disease is a major cause of impaired ulcer, wound healing and gangrenous diabetic foot ${ }^{\mathrm{vi}}$. In a review of 
global variation in incidence which included European countries and the United States found that annual incidence of amputation ranging from 4.6 to $960 / 10,000$ people with diabetes, but $85 \%$ of countries/states examined had an annual incidence, $100 / 10,000^{\text {vii }}$.

Sepsis in the diabetic foot is mainly due to chronic hyperglycaemia and superadded infections ${ }^{\text {viii. The }}$ most important intervention to prevent diabetic foot ulceration and its consequences is early recognition of high-risk patients and their risk factors and referral to appropriate medical departments ${ }^{i x}$, . High risk patients can be identified from the history of a previous ulcer or amputation and clinical examination, impaired monofilament sensation and vibration perception, absent Achilles tendon reflex, callus foot deformities, and absent pedal pulse ${ }^{\mathrm{xi}}$, xii.

There are various risk factors for major lower extremity amputations related to diabetic foot, which includes microvascular diseases, infections, long duration of diabetes, poor glycemic control, peripheral arterial disease, old age and associated cardiovascular comorbidities ${ }^{\text {xiii. }}$.

In a study it was found that foot ulcers occur in about $4-10 \%$ of people with diabetes. When foot ulcers do occur, the majority have a good outlook: 60-80 percent of foot ulcers will heal, 10-15\% will remain active and 5-24\% will eventually lead to limb amputation within 6-18 months of the initial evaluation $^{\text {xiv }}$. Social factors, such as low socioeconomic status, poor access to healthcare services, and poor education about diabetes are also related to more frequent foot ulceration ${ }^{\mathrm{xv}}$.

\section{MATERIAL AND METHODS}

Present study was conducted in the department of Medicine and Orthopaedics in Darbhanga Medical College Laheriasarai Darbhanga and Hospital. This observational study was done on the review of medical records of consecutive type 2 diabetic patients admitted in the hospital. Type 2 diabetic patients with intermittent claudication or rest pain without feet infections or issue loss were excluded from this study. Written informed consent was obtained from each patient included in the study. Patients not willing to give informed consent were excluded from the study.

Admitted patients were treated and managed according to the standard protocol of the hospital. History, clinical and physical examination were carried out on each patient. Ulcer characteristics like infection and depth of the ulcer, site of ulcer were assessed. Associated diabetic neuropathy and peripheral arterial disease was assessed by a clinical method. Age, sex, body mass index (BMI), smoking, duration of diabetes, diabetic control therapy, associated hypertension, cardiac diseases were recorded. The glycated hemoglobin level (HbA1c) were recorded.

Lower extremity amputation was defined as resection of any segment of the lower extremity with removal of the bone. Minor amputation was defined as any amputation that preserves the ankle joint with an intact healed wound. Major amputation was defined as any amputation that interferes with the ankle joint $^{\text {xvi }}$, vii, 18 .

\section{Data Analysis:}

Statistical analysis was done using SPSS software. Data were described using frequencies, percentages, and means. $P$-value $\leq 0.05$ was considered statistically significant.

\section{RESULTS}

A total of 128 patients with diabetic foot were included in the study of which 76(59.4\%) were male and $52(40.6 \%)$ were female. Of the 76 male $6(4.7 \%)$ had major amputation and out of 52 female 4(3.1\%) had major amputation, thus total number of major amputations were $10(7.8 \%)$

Table 1: Major amputation

\begin{tabular}{|l|l|l|l|}
\hline & Male & Female & total \\
\hline Amputation & $6(4.7 \%)$ & $4(3.1 \%)$ & $10(7.8 \%)$ \\
\hline No amputation & $70(54.7 \%)$ & $48(37.5 \%)$ & $118(92.2 \%)$ \\
\hline Total & $76(59.4 \%)$ & $52(40.6 \%)$ & $128(100 \%)$ \\
\hline
\end{tabular}


Dr. Kumar Durgeshwar et al, International Journal of Medical and Biomedical Studies (IJMBS)

Table 2: Major amputation according to patients' demographic and clinical characteristics

\begin{tabular}{|c|c|c|c|c|c|c|c|}
\hline \multirow[t]{3}{*}{ Variable } & \multicolumn{4}{|c|}{ Major amputation } & \multirow{2}{*}{\multicolumn{2}{|c|}{ Number of patients with diabetic foot }} & \multirow[t]{3}{*}{$P$-value } \\
\hline & \multicolumn{2}{|c|}{ No } & \multicolumn{2}{|c|}{ Yes } & & & \\
\hline & $\mathbf{n}$ & $\%$ & $n$ & $\%$ & $\mathrm{n}$ & $\%$ & \\
\hline \multicolumn{7}{|c|}{ Sex } & \multirow[t]{3}{*}{1} \\
\hline Male & 70 & $92 \%$ & 6 & $8 \%$ & 76 & $59 \%$ & \\
\hline Female & 48 & $92 \%$ & 4 & $8 \%$ & 52 & $41 \%$ & \\
\hline \multicolumn{7}{|c|}{ Age group } & \multirow[t]{3}{*}{0.6815} \\
\hline$\leq 60$ years & 98 & $92 \%$ & 8 & $8 \%$ & 106 & $83 \%$ & \\
\hline$>60$ years & 20 & $91 \%$ & 2 & $9 \%$ & 22 & $17 \%$ & \\
\hline \multicolumn{7}{|c|}{ Body mass index } & \multirow[t]{3}{*}{0.4551} \\
\hline$\leq 25 \mathrm{~kg} / \mathrm{m}^{2}$ & 25 & $89 \%$ & 3 & $11 \%$ & 28 & $22 \%$ & \\
\hline$>25 \mathrm{~kg} / \mathrm{m}^{2}$ & 93 & $93 \%$ & 7 & $7 \%$ & 100 & $78 \%$ & \\
\hline \multicolumn{7}{|c|}{ Duration of diabetes } & \multirow[t]{3}{*}{0.0052} \\
\hline$<10$ years & 89 & $97 \%$ & 3 & $3 \%$ & 92 & $72 \%$ & \\
\hline$\geq 10$ years & 29 & $81 \%$ & 7 & $19 \%$ & 36 & $28 \%$ & \\
\hline \multicolumn{7}{|c|}{ HbA1c } & \multirow[t]{3}{*}{0.0001} \\
\hline$<8.5 \%$ & 17 & $71 \%$ & 7 & $29 \%$ & 24 & $19 \%$ & \\
\hline$\geq 8.5 \%$ & 101 & $97 \%$ & 3 & $3 \%$ & 104 & $81 \%$ & \\
\hline \multicolumn{7}{|c|}{ Hypertension } & \multirow[t]{3}{*}{0.5137} \\
\hline No & 54 & $90 \%$ & 6 & $10 \%$ & 60 & $47 \%$ & \\
\hline Yes & 64 & $94 \%$ & 4 & $6 \%$ & 68 & $53 \%$ & \\
\hline \multicolumn{7}{|c|}{ Smoking } & \multirow[t]{3}{*}{0.7548} \\
\hline No & 65 & $93 \%$ & 5 & $7 \%$ & 70 & $55 \%$ & \\
\hline Yes & 53 & $91 \%$ & 5 & $9 \%$ & 58 & $45 \%$ & \\
\hline \multicolumn{7}{|c|}{ Cardiac diseases } & \multirow[t]{3}{*}{0.0346} \\
\hline No & 79 & $96 \%$ & 3 & $4 \%$ & 82 & $64 \%$ & \\
\hline Yes & 39 & $85 \%$ & 7 & $15 \%$ & 46 & $36 \%$ & \\
\hline \multicolumn{7}{|c|}{ Stroke } & \multirow[t]{3}{*}{0.0523} \\
\hline No & 109 & $94 \%$ & 7 & $6 \%$ & 116 & $91 \%$ & \\
\hline Yes & 9 & 72.2 & 3 & $25 \%$ & 12 & $9 \%$ & \\
\hline
\end{tabular}


Statistically significant difference was observed in $\mathrm{HbA} 1 \mathrm{C}$ and duration of diabetes group in amputation. High $\mathrm{HbA} 1 \mathrm{C}$ and more duration of diabetes was associated with the higher number of amputation. The rate of amputation was much higher among patients hypertension, smoking, cardiac diseases and stroke.

\section{DISCUSSION AND CONCLUSION}

The most common and significant risk factors for foot ulceration are diabetic neuropathy, peripheral arterial disease, and consequent traumas of the foot. In $90 \%$ of the cases neuropathy is the common factor, motor neuropathy causes muscle weakness, atrophy, and paresis while sensory neuropathy leads to loss of the protective sensation of pain, pressure, and heat. Autonomic dysfunction causes vasodilation and decreased sweating, resulting in a loss of skin integrity, which provides a site vulnerable to microbial infection ${ }^{\text {xviii. }}$.

Risk factors for foot ulceration are previous history of foot ulceration or amputation, visual impairment, diabetic nephropathy, poor glycemic control, and cigarette smoking. Some studies have shown that foot ulceration is more common in men with diabetes than in women ${ }^{\mathrm{xix}},{ }^{15}$. Similar results were observed in our study amputation and foot ulcers were more common in males as compared to females.

A Major lower limb amputation was observed in $10(7.8 \%)$ in our study of which $6(4.7 \%)$ were male and $4(3.1 \%)$ were female. Amputation rate in diabetic foot in other studies were from 4.25 to $27 \%^{\mathrm{xx}}$. Statistically significant relation was observed in amputed patients with higher level of $\mathrm{HbA} 1 \mathrm{C}$ and long duration of diabetes. Similar results were observed in other studies ${ }^{\mathrm{xxi}}$, xii. Associated cardiovascular factors, infections old age and male gender are risk factors observed in our study. Similar risk factors were reported by other authors ${ }^{\text {xiii }}$, xxiv.

To conclude poor glycemic controls and duration of diabetes are the important independent risk factors for diabetes-related major lower extremity amputations.

\section{REFERENCES}

1. Singh $N$, Armstrong DG, Lipsky BA.Preventing foot ulcers in patients with diabetes.JAMA. 2005 Jan 12; 293(2):217-28.

2. Siitonen $\mathrm{OI}$, Niskanen LK, Laakso $M$, Siitonen JT, Pyorala K: Lower-extremity amputations in diabetic and nondiabetic patients: a population-based study in eastern Finland. Diabetes Care 16:16-20, 1993

3. Kumar S, Ashe HA, Parnell LN, Fernando DJS, Tsigos C, Young RJ, Ward JD, Boulton AJM: The prevalence of foot ulceration and its correlates in type 2 diabetic patients: a population-based study. Diabet Med 11: 480-484, 1994

4. Trautner C, Haastert B, Giani G, Berger M: Incidence of lower limb amputations and diabetes. Diabetes Care 19:1006-1009, 1996

5. Reiber GE, Vileikyte L, Boyko EJ, del Aguila M, Smith DG, Lavery LA, Boulton AJ.Causal pathways for incident lower-extremity ulcers in patients with diabetes from two settings.Diabetes Care. 1999 Jan; 22(1):157-62.

6. Pecoraro RE, Reiber GE, Burgess EM. Pathways to diabetic limb amputation. Basis for prevention. Diabetes Care. 1990 May; 13(5):513-21.

7. Moxey PW, Gogalniceanu P, Hinchliffe RJ, et al. Lower extremity amputations a review of global variability in incidence. Diabet Med 2011;28: 1144-1153

8. Lipsky BA, Berendt AR, Cornia PB, Pile JC, Peters EJ, Armstrong DG, Deery HG, Embil JM, Joseph WS, Karchmer AW, Pinzur MS, Senneville E, Infectious Diseases Society of America.2012 Infectious Diseases Society of America clinical practice guideline for the diagnosis and treatment of diabetic foot infections.Clin Infect Dis. 2012 Jun; 54(12):e132-73

9. Bakker K, Dooren J: A specialized outpatient foot clinic for diabetic patients decreases the number of amputations and is cost saving. Ned Tijdschr Geneeskd 138:565-569, 1994

10. Mason J, O'Keeffe C, McIntosh A, Hutchinson A, Booth A, Young RJ: A systematic review of foot ulcer in patients with type 2 diabetes mellitus. I. Prevention. Diabet Med 16:801-812, 1999

11. The International Working Group on the Diabetic Foot: International Consensus on the Diabetic Foot Amsterdam, International Working Group on the Diabetic Foot, 1999

12. Boyko EJ, Ahroni J, Stensel V, Forsberg RC, Davignon DR, Smith DG: A prospective study of risk factors for diabetic foot ulcer. Diabetes Care 22:1036-1042, 1999

13. Shatnawi, N. J., Al-Zoubi, N. A., Hawamdeh, H. M., Khader, Y. S., Garaibeh, K., \& Heis, H. A. (2018). Predictors of major lower limb amputation in type 2 diabetic patients referred for hospital care with diabetic foot syndrome. Diabetes, metabolic syndrome and obesity : targets and therapy, 11, 313-319.

14. Alexiadou K, Doupis J. Management of diabetic foot ulcers. Diabetes Ther. 2012;3(1):4.

15. Prompers $L$, Huijberts $M$, Apelqvist J, Jude $E$, Piaggesi A, Bakker $K$, Edmonds $M$, Holstein $P$, Jirkovska $A$, Mauricio D, Ragnarson Tennvall G, Reike H, Spraul M, Uccioli L, Urbancic V, Van Acker K, van Baal J, van Merode F, Schaper N. High prevalence of ischaemia, 
infection and serious comorbidity in patients with diabetic foot disease in Europe. Baseline results from the Eurodiale study.Diabetologia. 2007 Jan; 50(1):1825.

16. Bakker K, Apelqvist J, Lipsky BA, Van Netten JJ, International Working Group on the Diabetic Foot.

17. The 2015 IWGDF guidance documents on prevention and management of foot problems in diabetes: development of an evidence-based global consensus. Diabetes Metab Res Rev. 2016 Jan; 32 Suppl 1():2-6.

18. Alvarsson A, Sandgren B, Wendel C, Alvarsson $M$, Brismar K. A retrospective analysis of amputation rates in diabetic patients: can lower extremity amputations be further prevented?Cardiovasc Diabetol. 2012 Mar 2; 11()$: 18$.

19. Brem $H$, Sheehan $P$, Boulton AJ. Protocol for treatment of diabetic foot ulcers.Am J Surg. 2004 May; 187(5A):1S-10S.

20. Benotmane A, Mohammedi F, Ayad F, Kadi K, Azzouz A. Diabetic foot lesions: etiologic and prognostic factors.Diabetes Metab. 2000 Apr; 26(2):113-7.

21. Thewjitcharoen $Y$, Krittiyawong $S$, Porramatikul $S$, Parksook W, Chatapat L, Watchareejirachot O, Sripatpong J, Himathongkam T. Outcomes of hospitalized diabetic foot patients in a multidisciplinary team setting: Thailand's experience.J Clin Transl Endocrinol. 2014 Dec; 1(4):187-191.

22. McNeely MJ, Boyko EJ, Ahroni JH, Stensel VL, Reiber GE, Smith DG, Pecoraro RF. The independent contributions of diabetic neuropathy and vasculopathy in foot ulceration. How great are the risks?Diabetes Care. 1995 Feb; 18(2):216-9.

23. Pscherer S, Dippel FW, Lauterbach S, Kostev $\mathrm{K}$. Amputation rate and risk factors in type 2 patients with diabetic foot syndrome under real-life conditions in Germany.Prim Care Diabetes. 2012 Oct; 6(3):241-6.

24. Lee JS, Lu M, Lee VS, Russell D, Bahr C, Lee ET. Lowerextremity amputation. Incidence, risk factors, and mortality in the Oklahoma Indian Diabetes Study.Diabetes. 1993 Jun; 42(6):876-82.

25. Pscherer S, Dippel FW, Lauterbach S, Kostev $\mathrm{K}$. Amputation rate and risk factors in type 2 patients with diabetic foot syndrome under real-life conditions in Germany.Prim Care Diabetes. 2012 Oct; 6(3):241-6. 